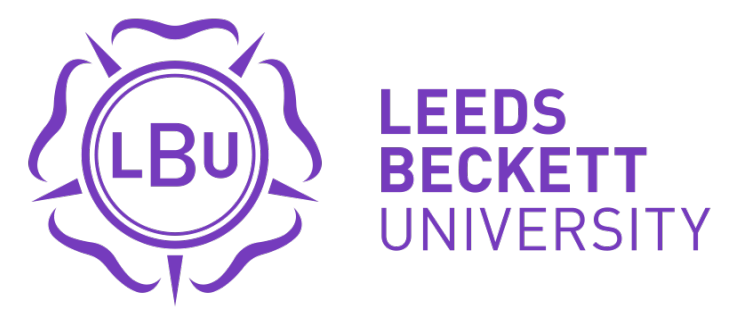

Citation:

Hanley, B and Bissas, A and Merlino, S and Gruber, AH (2019) Most marathon runners at the 2017 IAAF World Championships were rearfoot strikers, and most did not change footstrike pattern. Journal of Biomechanics, 92. pp. 54-60. ISSN 0021-9290 DOI: https://doi.org/10.1016/j.jbiomech.2019.05.024

Link to Leeds Beckett Repository record:

https://eprints.leedsbeckett.ac.uk/id/eprint/6018/

Document Version:

Article (Accepted Version)

Creative Commons: Attribution-Noncommercial-No Derivative Works 4.0

The aim of the Leeds Beckett Repository is to provide open access to our research, as required by funder policies and permitted by publishers and copyright law.

The Leeds Beckett repository holds a wide range of publications, each of which has been checked for copyright and the relevant embargo period has been applied by the Research Services team.

We operate on a standard take-down policy. If you are the author or publisher of an output and you would like it removed from the repository, please contact us and we will investigate on a case-by-case basis.

Each thesis in the repository has been cleared where necessary by the author for third party copyright. If you would like a thesis to be removed from the repository or believe there is an issue with copyright, please contact us on openaccess@leedsbeckett.ac.uk and we will investigate on a case-by-case basis. 


\title{
Most marathon runners at the 2017 IAAF World Championships were rearfoot strikers, and most did not change footstrike pattern
}

\author{
Original article
}

Brian Hanley ${ }^{1 *}$, Athanassios Bissas ${ }^{1}$, Stéphane Merlino ${ }^{2}$ and Allison H. Gruber ${ }^{3}$

${ }^{1}$ Carnegie School of Sport, Leeds Beckett University, United Kingdom

${ }^{2}$ International Association of Athletics Federations, Monaco

${ }^{3}$ Department of Kinesiology, Indiana University Bloomington, USA

* Corresponding author's details:

Brian Hanley,

Fairfax Hall,

Headingley Campus,

Leeds Beckett University,

LS6 3QS,

United Kingdom.

Telephone: +44 1138123577

Fax: +44 1132833170

Email: $\underline{\text { b.hanley@leedsbeckett.ac.uk }}$

Word count: 3497

Abstract word count: 238

Number of figures: 3

Number of tables: 4 


\section{Abstract}

The aim of this study was to analyze footstrike patterns in elite marathon runners at the 2017 IAAF World Championships. Seventy-one men and 78 women were analyzed in their respective races. Athletes' footstrike patterns were recorded $(120 \mathrm{~Hz})$ at approximately 8.5, 19, 29.5 and $40 \mathrm{~km}$ ("Laps $1-4$ ") and categorized as either rearfoot (RFS), midfoot or forefoot striking; the latter two were classified together as non-rearfoot striking (NRFS). The most common footstrike pattern was RFS, with proportions never less than $54 \%$ of men or $67 \%$ of women at any distance. There were no sex-based differences for proportion of footstrike patterns, and there were no differences between footstrike proportions when comparing the top and bottom 50\% of men finishers, or between women during Laps 1 and 2 . A greater proportion of the top $50 \%$ of women maintained NRFS than amongst the bottom $50 \%$. The proportion of RFS increased with distance run in the men's race, although more than $75 \%$ of athletes across both marathons had consistent footstrike patterns between laps (79 RFS and 36 NRFS). As most athletes were RFS (including the top four finishing men), there appears to be no clear advantage to NRFS in marathon running. Coaches should note that it is normal for elite marathon runners to be either RFS or NRFS; however, forefoot striking was rare. The high proportion of athletes who maintained their footstrike pattern reflected individualized preferences for a given footstrike pattern.

Keywords: athletics, biomechanics, endurance, fatigue, videography 


\section{Introduction}

At $42.195 \mathrm{~km}$ long, the marathon is the longest running race held at the Olympic Games and International Association of Athletics Federations (IAAF) World Championships. It differs from other championship running races by being more than four times longer than the next longest race, the $10,000 \mathrm{~m}$, and it is the only running race held on the road. The fatiguing nature of the marathon, with championship finishing times typically longer than 2:05:00 for men and 2:20:00 for women (IAAF, 2019a), leads to reduced running speeds in the second half and, for the world's best athletes, success is largely a case of avoiding slowing down toward the finish, rather than speeding up (Hanley, 2016). Elite marathon runners offset fatigue to some extent through nutritional strategies (e.g., carbohydrate drinks), tactics (e.g., even pacing) and, of particular interest to biomechanists, potentially by choosing a gait mode that enhances elastic energy storage and return from lower limb muscle-tendon units.

It has been proposed that an anterior footstrike position (midfoot or forefoot striking) provides an advantage over rearfoot striking (RFS) through greater storage and release of elastic energy in the Achilles tendon and foot arches (Perl et al., 2012). Elastic strain work in the tendons and contractile components of muscles can account for about half of total mechanical work performed during running, particularly at faster speeds (Cavagna et al., 1964; Cavagna and Kaneko, 1977). This mechanism is theorized to be enhanced during forefoot striking (FFS) partly because the heel descends substantially under controlled dorsiflexion, stretching the Achilles tendon while the triceps surae acts eccentrically or isometrically, with the foot arches loaded at initial contact (Perl et al., 2012). Although a theorized enhancement of this mechanism with a midfoot striking (MFS) or FFS pattern might positively influence running economy, Kubo et al. (2015) did not find any differences in morphological or mechanical properties of the Achilles tendon between FFS, MFS and 
RFS, and studies comparing whole-body submaximal oxygen consumption have not found MFS or FFS to be more economical than RFS when comparing runners habituated to each footstrike pattern, or habitual versus converted strike patterns (Ardigò et al., 1995; Cunningham et al., 2010; Di Michele and Merni, 2014; Gruber et al., 2013; Ogueta-Alday et al., 2014; Perl et al., 2012). This result can be partially explained by the similarity in total lower limb mechanical work or mean power between footstrike patterns (at $16.2 \mathrm{~km} \cdot \mathrm{h}^{-1}$ (Stearne et al., 2014)) or a trade-off in knee versus ankle joint stiffness (Hamill et al., 2014). Interestingly, Gruber et al. (2013) found that carbohydrate oxidation rates were greater during FFS than RFS, and that FFS was less economical at running speeds of $14.4 \mathrm{~km} \cdot \mathrm{h}^{-1}$. Despite the theorized benefit of enhanced storage and release of elastic strain energy with an anterior footstrike, there is little evidence that one footstrike pattern results in greater whole-body running economy (Ardigò et al., 1995; Gruber et al., 2013).

Distance runners can make initial contact with the rearfoot (heel striking), midfoot or forefoot (Di Michele and Merni, 2014; Ogueta-Alday et al., 2014), with the proportion of RFS increasing over longer distances and slower recreational running speeds (Forrester et al., 2015; Hasegawa et al., 2007; Kasmer et al., 2014). Hayes and Caplan (2012) analyzed 181 competitive club runners at a British Miler's Club meet of $800 \mathrm{~m}$ and $1500 \mathrm{~m}$ races (mean speeds faster than $22.90 \mathrm{~km} \cdot \mathrm{h}^{-1}$ for men, and $19.87 \mathrm{~km} \cdot \mathrm{h}^{-1}$ for women), finding that $27 \%$ of athletes were RFS, 42\% MFS and 31\% FFS. By contrast, at the $15 \mathrm{~km}$ distance in the Sapporo International half marathon race $(21.095 \mathrm{~km})$, the 50 highest-finishing men and the seven highest-finishing women analyzed were more likely to be MFS (37\%) than slower competitors, but very few (4\%) were FFS (Hasegawa et al., 2007). In the Manchester City Marathon, Larson et al. (2011) found that $93 \%$ of recreational runners (mean finishing time: 3:57:31) adopted RFS at the $32 \mathrm{~km}$ distance, with many switching from MFS or FFS at 10 
$\mathrm{km}$. Marathon runners who use MFS or FFS during the early stages might later switch to RFS (Larson et al., 2011) because this leads to longer contact times and increased economy (Gruber et al., 2013). Additionally, a shift toward RFS would be necessary as continuous FFS results in increased plantarflexor work (Baggaley et al., 2017) and can result in considerable fatigue in the contractile properties of the muscle, but not the tendon (Peltonen et al., 2012). Thus, a change in footstrike pattern during a long, submaximal run might be consistent with redistributing mechanical work to proximal leg muscles during a prolonged fatiguing run (Sanno et al., 2018). Although most recreational runners adopt RFS, the proportion of worldclass marathon runners adopting MFS or FFS might be higher given the hypothesized energy return benefits (Kubo et al., 2015), their greater running speeds, and coaches' recommendations to avoid RFS (Anderson, 2018).

Recreational and high-caliber club runners have been analyzed during good-standard races of varying distance; footstrike patterns have also been reported for laboratory testing using treadmills (Hanley and Tucker, 2018; Kubo et al., 2015) and an indoor runway (Preece et al., 2018). However, no previous research has analyzed the footstrike patterns of world-class marathon runners, or the changes that occur, as they complete a World Championship race. Measuring footstrike patterns during marathon races at World Championships ensures the highest possible ecological validity, as it allows for analysis of runners in their "natural environment". This invaluable provision that laboratory-based studies cannot offer produces real-world data for coaches, scientists and other practitioners to base their training and applications on. The aim of this novel study was to analyze and compare footstrike patterns in elite men and women marathon runners at the 2017 IAAF World Championships at four distances throughout the race, and to compare between higher- and lower-finishing athletes. Comparisons were also made using the present study's results with previous research on 
races of different lengths and athlete standards. Because the sample comprised elite marathon runners, it was hypothesized that most athletes would adopt MFS or FFS, and that the proportion of RFS would increase with distance run.

\section{Methods}

\subsection{Participants}

Data were collected as part of the London 2017 World Championships Biomechanics Project, and the use of those data was approved by the IAAF, who control the data, and locally through the institution's research ethics procedures. Seventy-one men and 78 women were analyzed in their respective races, held on the same day and on the same course. Athletes who did not finish (27 men and 20 women) were not analyzed. Personal best (PB) and finishing times were obtained from the open-access IAAF website (IAAF, 2019a; 2019b) for competitors in both races; no PB was reported for one man.

\subsection{Protocol}

The men's and women's marathon races were held on a course that comprised four approximately 10.5-km loops (“Laps $1-4$ "), with the remaining distance comprising a section that led from the start / finish line to the beginning of the loop. A section of straight, wide road near the end of the loop was chosen for video capture so that data collection occurred at approximately 8.5, 19, 29.5 and $40 \mathrm{~km}$. Two Casio Exilim high-speed cameras (Casio, Tokyo, Japan) operating at $120 \mathrm{~Hz}$ (shutter speed: 1/1000 s; ISO: variable; 640x480 px) were placed about $1 \mathrm{~m}$ apart on the side of the street farthest from the athletes' running line (marked with blue paint by the organizers). The cameras were positioned approximately $0.30 \mathrm{~m}$ above the running surface on tripods with their optical axes perpendicular to the running direction. To assist in identifying athletes, two Sony NXCAM HXR-NX3 cameras 
(Sony, Tokyo, Japan) were used (sampling rate: $50 \mathrm{~Hz}$; shutter speed: 1/1250 s; ISO: variable; FHD: $1920 \times 1080 \mathrm{px}$ ) and angled at approximately $45^{\circ}$ and $135^{\circ}$ to the plane of motion.

\subsection{Data processing}

All videos were analyzed using SIMI Motion version 9.2.2 (Simi Reality Motion Systems GmbH, Unterschleissheim, Germany). Athletes' race positions within each lap were first identified using the Sony NXCAM footage, with their shoe brand, shoe color (no athletes ran barefoot) and shorts color recorded to confirm runners' identities. The split times for all athletes at 10, 20, 30 and $40 \mathrm{~km}$ (IAAF, 2019a) were also used to identify athletes' positions. As with similar research conducted in competition (Hayes and Caplan, 2012; Larson et al., 2011), footstrike patterns were defined using the foot position at first contact with the ground using the methods of Hasegawa et al. (2007) as either: RFS (the heel contacted the ground first without simultaneous contact by the midfoot or forefoot), MFS (the heel and midfoot, or occasionally the entire sole, contacted the ground together) or FFS (the forefoot / front half of the sole contacted the ground first with a clear absence of heel contact). In this study, the heel was considered the end one-third of the shoe, with a gap from the rest of the sole typically visible on the underneath. Footstrike patterns were obtained in nearly all cases using the Casio Exilim cameras although, for three athletes trailed off the back of the field, footstrikes were identified using footage from the Sony NXCAM cameras.

\subsection{Analysis}

Pearson's chi-squared test of association $\left(\chi^{2}\right)$ compared observed counts of categorical data (e.g., percentages of athletes who were RFS) between men and women, between the top 50\% (men: $\mathrm{N}=36$; women: $\mathrm{N}=39$ ) and bottom $50 \%$ of finishers in each race (men: $\mathrm{N}=35$; 
women: $\mathrm{N}=39$ ), and between the values found in this study and previous research. Comparisons with previous studies included results from middle-distance races (Hayes and Caplan, 2012), a half marathon (Hasegawa et al., 2007), a marathon (Larson et al., 2011) and an ultramarathon (Kasmer et al., 2014). For these comparisons, the total values reported are used, except for the Hasegawa et al. (2007) half-marathon data taken from the 50 highestfinishing men and the seven highest-finishing women who could be analyzed. Because it was not possible to tell what mixed footstrike patterns occurred in some studies, athletes with asymmetrical footstrikes were not included.

Five men and five women had different footstrike patterns on each leg for some laps, and for statistical analysis were designated as 0.5 for the footstrike type performed by each foot. Of these ten runners, eight were asymmetrical on a single lap only (Lap 1, 2 or 3), and the others were asymmetrical for the first two laps only. Cochran's Q was used to measure whether the proportion of athletes who had each type of footstrike pattern changed during the race (Laps $1-4)$. Statistical significance was accepted as $\mathrm{p}<0.05$.

\section{Results}

The mean ( \pm 1 standard deviation) PB (h:min:s) for finishers was 2:13:33 ( \pm 4:08) in the men's race, and 2:32:53 ( \pm 7:19) in the women's race. The mean finishing times and the percentages of PB for all finishers, and the top $50 \%$ and bottom $50 \%$ of athletes, are shown in Table 1. Overall, five men and four women ran PBs. The numbers and percentages of men and women finishers displaying each type of footstrike pattern are shown in Table 2. Because there were so few FFS athletes, their values were included with the MFS athletes for the purposes of statistical analysis and together are referred to as "non-rearfoot striking" (NRFS). Cochran's Q test determined that there was an increase in the proportion of all men who were 
RFS with distance run $\left(\chi^{2}=9.33, p=0.025\right)$, but there was no change found amongst women (Table 2). There was no difference between men and women for the proportions of either type of footstrike pattern for the race overall or within each lap.

Regarding consistency of footstrike patterns between measurement distances (Figure 1), 34 men (48\% of all finishers) were RFS at all four measurement distances (including the top four men), whereas 21 men (30\%) were NRFS at all four distances. Regarding the women's footstrike patterns, 45 (58\% of all finishers) were RFS and 15 (19\%) were NRFS at all four measurement distances.

Across all four laps in the men's race, there was no difference in the proportion of athletes who were RFS or NRFS between the top $50 \%$ and bottom $50 \%$ (Table 3). Similarly, there was no difference between the top and bottom $50 \%$ in the proportions of RFS and NRFS in the women's race during Laps 1 and 2 (Table 3). However, more of the bottom $50 \%$ of women were RFS during Laps $3\left(\chi^{2}=4.41, p=0.036\right)$ and $4\left(\chi^{2}=7.89, p=0.005\right)$. Regarding consistency of footstrike patterns amongst top and bottom 50\% finishers (Figures 2 and 3), 16 (44\%) of the top $50 \%$ men and $18(51 \%)$ of the bottom $50 \%$ men were RFS at all four measurement distances, whereas $10(28 \%)$ of the top 50\% men and $11(31 \%)$ of the bottom $50 \%$ men were NRFS. Regarding the women's footstrike patterns, 17 (44\%) of the top 50\% and $28(72 \%)$ of the bottom $50 \%$ were RFS at all four measurement distances, whereas 12 $(31 \%)$ of the top $50 \%$ women and $3(8 \%)$ of the bottom $50 \%$ women were NRFS. The women in the bottom $50 \%$ were more likely to be RFS throughout the race than women in the top $50 \%\left(\chi^{2}=8.03, p=0.005\right)$; no differences were found amongst the men. Comparisons with previous studies are shown in Table 4. 


\section{Discussion}

The aim of this study was to analyze and compare footstrike patterns in men and women marathon runners at the 2017 IAAF World Championships at four distances throughout the race, and to compare between higher- and lower-finishing athletes. The hypothesis that most athletes would adopt MFS or FFS (i.e., NRFS) was rejected, as the most common footstrike pattern amongst this elite cohort was RFS: its proportion was never less than $54 \%$ of all men or $67 \%$ of women. Additionally, no differences were found between men and women for the proportions who had either type of footstrike pattern (RFS vs. NRFS). The proportion of RFS found in the present study was greater than in high-caliber club middle-distance racing (Hayes and Caplan, 2012), but less than amongst recreational marathon runners (Larson et al., 2011) and ultramarathon runners (Kasmer et al., 2014). However, the proportion of RFS athletes was similar to elite half marathon runners (Hasegawa et al., 2007). Taken together, these results suggest that runners of any training status competing over longer distances are more likely to be RFS, but also that the proportion of RFS is lowest amongst better athletes (i.e., 60-65\% compared with $89-96 \%$ in recreational athletes). Championship marathon racing differs from large, city-based marathons that use pre-arranged pacemakers to help the top athletes achieve fast times (Erdmann and Lipinska, 2013). The finding that most athletes analyzed in the present study had finishing times slower than PB time reflects this difference in racing and indicates a more conservative approach to racing. A limitation of this study is that it was not possible to measure running speeds, and thus any changes in footstrike pattern that occurred because of the changes in pace typical of championship racing cannot be accounted for. That athletes ran slightly slower than their PB times might partially explain the greater proportion of RFS compared with shorter distance races (Hayes and Caplan, 2012), but even at faster marathon paces it is unlikely that athletes would drastically alter their 
footstrike patterns. Coaches should note that it is therefore normal for relatively high proportions of both NRFS and RFS to be found in elite marathoners.

In this World Championships, there were no differences between proportions of NRFS and RFS between the top and bottom $50 \%$ of men at any distance. In the women's race, a greater proportion of the top $50 \%$ maintained NRFS than amongst the bottom $50 \%$. Additionally, there was a greater proportion of RFS during laps 3 and 4 within the bottom $50 \%$ than the top $50 \%$, but no difference in RFS distribution between abilities before Lap 3. Given that shifts in joint work during a prolonged run might be experience-related (Sanno et al., 2018), the reduced ability of the bottom $50 \%$ of women to maintain footstrike patterns might be because of a smaller depth of field in the women's event. Even though there were differences from lower-ability marathon runners (Larson et al., 2011), the present results suggest that there was no clear link between footstrike pattern and marathon racing ability amongst elite marathon runners. Given this finding, and considering that most athletes were RFS (including the top four finishing men), there appears to be no clear competitive advantage to NRFS over RFS for the men's elite marathon, but more research is needed to examine footstrike behaviors amongst competitive running women. This result does not suggest that there are no possible mechanical or metabolic advantages of specific footstrike patterns, but that each individual adopts the footstrike pattern that is most suitable for their running style. It is possible that the harder road surface of marathon courses encouraged the wearing of footwear that cushions the athlete when landing, which possibly reduced the muscular activity required to attenuate impact shock (Boyer et al., 2004; Frederick et al., 1983) and allowed for the selection of a gait pattern that was optimized for running economy (Miller and Hamill, 2015), a key physiological parameter in marathon running (Midgley et al., 2007). 
Overall, more than $75 \%$ of athletes $(115 / 149)$ had consistent footstrike pattern between laps. In other words, less than one quarter (34/149) of all athletes changed footstrike pattern during the race. The results showed that $34(92 \%)$ of 37 men classified as RFS and $21(66 \%)$ of 32 classified as NRFS during Lap 1 maintained their footstrike pattern; in the women's race, the respective numbers were $45(88 \%)$ of 51 RFS and $15(60 \%)$ of 25 NRFS. Only one man and five women identified as RFS during Lap 1 switched to NRFS (on both legs) later in the race; thus, nearly all footstrike alterations were from NRFS to RFS. This directionality in switching footstrike pattern can be explained by: first, the lack of metabolic benefit when imposing NRFS in habitual rearfoot runners at the end of a prolonged run (Melcher et al., 2017) (although the athletes in this study ran with a freely-chosen footstrike pattern); second, by the neuromuscular fatigue experienced as a result of prolonged FFS (Peltonen et al., 2012); and third, by a shift from ankle to hip and knee joint work during a prolonged fatiguing run (Sanno et al., 2018). In particular, the greater plantarflexor muscular activity observed during NRFS (Yong et al., 2014) could explain why more NRFS runners altered their footstrike pattern during the later laps of the marathon than those who started with RFS. At the onset of fatigue, it might be difficult to maintain the plantarflexor eccentric actions required during NRFS, and the decrease in plantarflexor torques and muscle activity after switching from NRFS to RFS late in a prolonged run (Jewell et al., 2017) could therefore be a mechanism to delay the onset of complete exhaustion. The lower rate of carbohydrate oxidation with RFS (Gruber et al., 2013), and the selection of RFS when optimizing for metabolic cost (Miller and Hamill, 2015), support the use of RFS when attempting to delay fatigue. However, the greater proportion of runners who maintained their footstrike pattern throughout the race (including NRFS) compared with recreational athletes (Larson et al., 2011) might be reflective of the world-class runners observed in this study given that the distal to proximal shift in joint work during a fatiguing run is more pronounced in 
recreational runners (Sanno et al., 2018). The runners observed in the present study maintained their footstrike pattern possibly because they adopted strategies to delay the onset of fatigue-related alterations in gait and / or combat the physical pain associated with the onset of fatigue, and this consistency was likely developed during the considerable training undertaken in preparation for the marathon, and throughout their running careers.

The participants in this study were analyzed within the setting of a major championship where athletes had to achieve a qualifying standard to take part, giving this new research high ecological validity. This study did not have an intervention (e.g., the athletes were not required to try different footstrike patterns or footwear) or analyze the athletes' running history (e.g., whether they ran barefoot as children), and thus is not intended to infer that these particular athletes would achieve better running times or suffer fewer injuries should they adopt particular footstrike patterns. Indeed, the high proportion of all runners who maintained their footstrike pattern throughout the race is reflective of individualized preferences for a given footstrike pattern, and runners of all abilities should note that adopting an approach to technique that suits their physique and fitness is probably the most sensible approach. For coaches, biomechanists and similar professions, these findings suggest there is no one optimal footstrike pattern with regard to performance, and athletes should not be overly encouraged to alter what comes naturally to them.

\section{Conflict of interest statement}

The authors have no conflicts of interest that are relevant to the findings of this manuscript. The data collection and initial data analysis were supported by funding provided by the IAAF as part of a wider development / education project; however, the nature of the data is purely descriptive and not associated with any governing body, commercial sector or product. No 
funding was provided for the writing of this manuscript. The results of the present study do not constitute endorsement by the IAAF. 


\section{References}

Anderson, O., 2018. Running form: How to run faster and prevent injury. Human Kinetics, Champaign, IL.

Ardigò, L.P., LaFortuna, C., Minetti, A.E., Mognoni, P., Saibene, F., 1995. Metabolic and mechanical aspects of foot landing type, forefoot and rearfoot strike, in human running. Acta Physiol. 155, 17-22. doi: 10.1111/j.1748-1716.1995.tb09943.x

Baggaley, M., Willy, R.W., Meardon, S.A., 2017. Primary and secondary effects of real-time feedback to reduce vertical loading rate during running. Scand. J. Med. Sci. Sports 27, 501507. doi: $10.1111 / \mathrm{sms} .12670$

Boyer, K.A., Nigg, B.M., 2004. Muscle activity in the leg is tuned in response to impact force characteristics. J. Biomech. 37, 1583-1588. doi: 10.1016/j.jbiomech.2004.01.002

Cavagna, G.A., Saibene, F.P., Margaria, R., 1964. Mechanical work in running. J. Appl. Physiol. 19, 249-256. doi: 10.1152/jappl.1964.19.2.249

Cavagna, G.A., Kaneko, M., 1977. Mechanical work and efficiency in level walking and running. J. Physiol. 268, 467-481. doi: 10.1113/jphysiol.1977.sp011866

Cunningham, C.B., Schilling, N., Anders, C., Carrier, D.R., 2010. The influence of foot posture on the cost of transport in humans. J. Exp. Biol. 213, 790-797. doi: $10.1242 /$ jeb. 038984 
Di Michele, R., Merni, F. 2014. The concurrent effects of strike pattern and ground-contact time on running economy. J. Sci. Med. Sport 17, 414-418. doi: 10.1016/j.jsams.2013.05.012

Erdmann, W.S., Lipinska, P. 2013. Kinematics of marathon running tactics. Hum. Move. Sci. 32, 1379-1392. doi: 10.1016/j.humov.2013.07.006

Forrester, S.E., Townend, J., 2015. The effect of running velocity on footstrike angle - a curve-clustering approach. Gait Posture 41, 26-32. doi: 10.1016/j.gaitpost.2014.08.004

Frederick, E.C., Clarke, T.E., Larsen J.L., Cooper, L.B., 1983. The effects of shoe cushioning on the oxygen demands of running. In: Nigg, B., Kerr, B. (Eds.), Biomechanical Aspects of Sports Shoes and Playing Surfaces. University of Calgary Printing Services, Calgary, pp. 107-114.

Gruber, A.H., Umberger, B.R., Braun, B., Hamill, J. 2013. Economy and rate of carbohydrate oxidation during running with rearfoot and forefoot running patterns. J. Appl. Physiol. 115, 194-201. doi: 10.1152/japplphysiol.01437.2012

Hamill, J., Gruber, A.H., Derrick, T.R., 2014. Lower extremity joint stiffness characteristics during running with different footfall patterns. Eur. J. Sport Sci. 14, 130-136. doi: $10.1080 / 17461391.2012 .728249$

Hanley, B., Tucker, C.B., 2018. Gait variability and symmetry remain consistent during highintensity $10,000 \mathrm{~m}$ treadmill running. J. Biomech. 79, 129-134. doi: 10.1016/j.jbiomech.2018.08.008 
Hanley, B., 2016. Pacing, packing and sex-based differences in Olympic and IAAF World Championship marathons. J. Sports Sci. 34, 1675-1681. doi: $10.1080 / 02640414.2015 .1132841$

Hasegawa, H., Yamauchi, T., Kraemer, W.J., 2007. Foot strike patterns of runners at the 15$\mathrm{km}$ point during an elite-level half marathon. J. Strength Cond. Res. 21, 888-893.

Hayes, P., Caplan, N. 2012. Foot strike patterns and ground contact times during high-calibre middle-distance races. J. Sports Sci. 30, 1275-1283. doi: 10.1080/02640414.2012.707326

IAAF (2019a). Competition archive. Retrieved from http://www.iaaf.org/results?\&subcats=WCH,OLY

IAAF (2019b). Athletes. Retrieved from https://www.iaaf.org/athletes Jewell, C., Boyer, K.A., Hamill, J., 2017. Do footfall patterns in forefoot runners change over an exhaustive run? J. Sports Sci. 35, 74-80. doi: 10.1080/02640414.2016.1156726

Kasmer, M.E., Wren, J.J., Hoffman, M.D., 2014. Foot strike patterns and gait changes during a 161-km ultramarathon. J. Strength Cond. Res. 28, 1343-1350. doi: 10.1519/JSC.0000000000000282 
Kubo, K., Miyazaki, D., Shigeharu, T., Shimoju, S., Tsunoda, N. 2015. Relationship between Achilles tendon properties and foot strike patterns in long-distance runners. J. Sports Sci. 33, 665-669. doi: 10.1080/02640414.2014.962576

Larson, P., Higgins, E., Kaminski, J., Decker, T., Preble, J., Lyons, D., McIntyre, K., Normile, A. 2011. Foot strike patterns of recreational and sub-elite runners in a long-distance road race. J. Sports Sci. 29, 1665-1673. doi: 10.1080/02640414.2011.610347

Melcher, D.A., Paquette, M.R., Schilling B.K., Bloomer, R.J., 2017. Joint stiffness and running economy during imposed forefoot strike before and after a long run in rearfoot strike runners. J. Sports Sci. 35, 2297-2303. doi: 10.1080/02640414.2016.1266016

Midgley, A.W., McNaughton, L.R., Jones, A.M., 2007. Training to enhance the physiological determinants of long-distance running performance: Can valid recommendations be given to runners and coaches based on current scientific knowledge? Sports Med., 37, 857-880. doi: $10.2165 / 00007256-200737100-00003$

Miller, R.H., Hamill, J., 2015. Optimal footfall patterns for cost minimization in running. J. Biomech. 48, 2858-2864. doi: 10.1016/j.jbiomech.2015.04.019

Ogueta-Alday, A., Rodríguez-Marroyo, J.A., García-López, J., 2014. Rearfoot striking runners are more economical than midfoot strikers. Med. Sci. Sports Exerc. 46, 580-585. doi: 10.1249/MSS.0000000000000139 
Peltonen, J., Cronin, N.J., Stenroth, L., Finni, T., Avela, J., 2012. Achilles tendon stiffness is unchanged after one hour in a marathon. J. Exp. Biol. 215, 3665-3671. doi: $10.1242 /$ jeb.068874

Perl, D.P., Daoud, A.I., Lieberman, D.E., 2012. Effects of footwear and strike type on running economy. Med. Sci. Sports Exerc. 44, 1335-1343. doi: 10.1249/MSS.0b013e318247989e

Preece, S.J., Bramah, C., Mason, D., 2018. The biomechanical characteristics of highperformance endurance running. Eur. J. Sport Sci., doi: 10.1080/17461391.2018.1554707

Sanno, M., Willwacher, S., Epro, G., Brüggemann, G.-P., 2018. Positive work contribution shifts from distal to proximal joints during a prolonged run. Med. Sci. Sports Exerc. 50, 2507-2517. doi: 10.1249/MSS.0000000000001707

Stearne, S.M., Alderson, J.A., Green, B.A., Donnelly, C.J., Rubenson, J., 2014. Joint kinetics in rearfoot versus forefoot running: implications of switching technique. Med. Sci. Sports Exerc. 46, 1578-1587. doi: 10.1249/MSS.0000000000000254

Yong, J.R., Silder, A., Delp, S.L., 2014. Differences in muscle activity between natural forefoot and rearfoot strikers during running. J. Biomech. 47, 3593-3597. doi: 10.1016/j.jbiomech.2014.10.015 
Table 1. Mean ( \pm SD) finishing times (h:min:s) and finishing times as a percentage of personal best (PB) for all finishers, and for each group of men and women.

$\begin{array}{lll}\text { All finishers } & \text { Top } 50 \% & \text { Bottom } 50 \%\end{array}$

\begin{tabular}{lccc}
\hline & $\mathrm{N}=71$ & $\mathrm{M}$ & \\
& $2: 20: 20( \pm 7: 18)$ & $2: 14: 58( \pm 2: 56)$ & $\mathrm{N}=35$ \\
Time & $105.1 \%( \pm 4.4)$ & $102.8 \%( \pm 2.3)$ & $107.4 \%( \pm 4.9)$ \\
$\%$ of PB & $\mathrm{N}=78$ & $\mathrm{~N}=39$ & $\mathrm{~N}=39$ \\
& $2: 41: 20( \pm 10: 23)$ & $2: 33: 13( \pm 4: 20)$ & $2: 49: 26( \pm 7: 55)$ \\
& $105.5 \%( \pm 3.8)$ & $103.9 \%( \pm 2.7)$ & $107.1 \%( \pm 4.1)$ \\
\hline Time & & & \\
\hline
\end{tabular}


Table 2. The number (and percentage) of men and women with each type of footstrike pattern during each analyzed lap. Values ending in .5 occurred as a small number of athletes had different footstrike patterns on each leg. Total percentages per lap do not always add up to $100 \%$ because of rounding. Athletes who did not finish the race were not included.

\begin{tabular}{lcccccccc}
\hline & \multicolumn{3}{c}{ Men $(\mathrm{N}=71)$} & \multicolumn{5}{c}{ Women (N=78) } \\
& Lap 1 & Lap 2 & Lap 3 & Lap 4* & Lap 1 & Lap 2* & Lap 3 & Lap 4 \\
RFS & 38 & 41.5 & 43 & 47 & 52 & 54 & 53.5 & 57 \\
& $(54 \%)$ & $(58 \%)$ & $(61 \%)$ & $(67 \%)$ & $(67 \%)$ & $(70 \%)$ & $(69 \%)$ & $(73 \%)$ \\
MFS & 31 & 25.5 & 25 & 21 & 22 & 21 & 22.5 & 19 \\
& $(44 \%)$ & $(36 \%)$ & $(35 \%)$ & $(30 \%)$ & $(28 \%)$ & $(27 \%)$ & $(29 \%)$ & $(24 \%)$ \\
FFS & 2 & 4 & 3 & 2 & 4 & 2 & 2 & 2 \\
& $(3 \%)$ & $(6 \%)$ & $(4 \%)$ & $(3 \%)$ & $(5 \%)$ & $(3 \%)$ & $(3 \%)$ & $(3 \%)$ \\
\hline
\end{tabular}

* One athlete was not recorded during this lap. 
Table 3. The number (and percentage) of men and women finishing in either the top $50 \%$ or bottom $50 \%$ with each type of footstrike pattern during each analyzed lap. Values ending in .5 occurred as a small number of athletes had different footstrike patterns on each leg. Total percentages per lap do not always add up to $100 \%$ because of rounding. Athletes who did not finish the race were not included.

\begin{tabular}{|c|c|c|c|c|c|c|c|c|}
\hline & \multicolumn{4}{|c|}{$\operatorname{Men}(\mathrm{N}=71)$} & \multicolumn{4}{|c|}{ Women $(\mathrm{N}=78)$} \\
\hline & Lap 1 & Lap 2 & Lap 3 & Lap 4* & Lap 1 & Lap 2* & Lap 3 & Lap 4 \\
\hline \multicolumn{9}{|c|}{ Top 50\% } \\
\hline \multirow{2}{*}{ RFS } & 19.5 & 20.5 & 20 & 23 & 22 & 24.5 & 22.5 & 23 \\
\hline & $(54 \%)$ & $(57 \%)$ & $(56 \%)$ & $(66 \%)$ & $(56 \%)$ & $(63 \%)$ & $(58 \%)$ & $(59 \%)$ \\
\hline \multirow{2}{*}{ MFS } & 15.5 & 13.5 & 14 & 11 & 16 & 13.5 & 15.5 & 15 \\
\hline & $(43 \%)$ & $(38 \%)$ & $(39 \%)$ & $(31 \%)$ & $(41 \%)$ & $(35 \%)$ & $(40 \%)$ & $(38 \%)$ \\
\hline \multirow{2}{*}{ FFS } & 1 & 2 & 2 & 1 & 1 & 1 & 1 & 1 \\
\hline & $(3 \%)$ & $(6 \%)$ & $(6 \%)$ & $(3 \%)$ & $(3 \%)$ & $(3 \%)$ & $(3 \%)$ & $(3 \%)$ \\
\hline
\end{tabular}

\section{Bottom 50\%}

\begin{tabular}{lcccccccc} 
& 18.5 & 21 & 23 & 24 & 30 & 29.5 & $31^{\dagger}$ & $34^{\dagger}$ \\
& $(53 \%)$ & $(60 \%)$ & $(66 \%)$ & $(69 \%)$ & $(77 \%)$ & $(78 \%)$ & $(79 \%)$ & $(87 \%)$ \\
MFS & 15.5 & 12 & 11 & 10 & 6 & 7.5 & 7 & 4 \\
& $(44 \%)$ & $(34 \%)$ & $(31 \%)$ & $(29 \%)$ & $(15 \%)$ & $(20 \%)$ & $(18 \%)$ & $(10 \%)$ \\
FFS & 1 & 2 & 1 & 1 & 3 & 1 & 1 & 1 \\
& $(3 \%)$ & $(6 \%)$ & $(3 \%)$ & $(3 \%)$ & $(8 \%)$ & $(3 \%)$ & $(3 \%)$ & $(3 \%)$ \\
\hline
\end{tabular}

* One athlete was not recorded during this lap.

${ }^{\dagger}$ Significantly different from Top $50 \%$ proportion of RFS $(p<0.01)$.

$\$$ Significantly different from Top $50 \%$ proportion of RFS $(p<0.05)$. 
Table 4. Comparisons between footstrike patterns found in the present study and previous research across race distances: total number $(\mathrm{N})$ and RFS as a proportion of all athletes (\%). Athletes with asymmetrical footstrike patterns are not included in any study's values shown below. The measurement distance selected for comparison is shown with the total race distance. The data shown for the Hasegawa et al. (2007) study are for the 50 highest-finishing men and seven highest-finishing women who could be analyzed.

\begin{tabular}{|c|c|c|c|c|c|}
\hline & $\begin{array}{l}\text { Present } \\
\text { study }\end{array}$ & $\begin{array}{l}\text { Kasmer et } \\
\text { al. (2014) }\end{array}$ & $\begin{array}{l}\text { Larson et al. } \\
\text { (2011) }\end{array}$ & $\begin{array}{l}\text { Hasegawa } \\
\text { et al. (2007) }\end{array}$ & $\begin{array}{c}\text { Hayes \& } \\
\text { Caplan (2012) }\end{array}$ \\
\hline & $\begin{array}{l}\text { Marathon } \\
(29.5 \mathrm{~km})\end{array}$ & $\begin{array}{l}\text { Ultra- } \\
\text { marathon } \\
(90.3 \mathrm{~km})\end{array}$ & $\begin{array}{l}\text { Marathon } \\
(32 \mathrm{~km})\end{array}$ & $\begin{array}{c}\text { Half } \\
\text { marathon } \\
(15 \mathrm{~km})\end{array}$ & $\begin{array}{l}800 / 1500 \mathrm{~m} \\
\text { (once per lap) }\end{array}$ \\
\hline RFS (N) & 95 & 251 & 266 & 34 & 44 \\
\hline NRFS (N) & 51 & 19 & 10 & 23 & 137 \\
\hline RFS (\%) & 65 & 89 & 96 & 60 & 24 \\
\hline$\chi^{2}(1)$ & & $52.68^{\S}$ & $75.69^{\S}$ & 0.52 & $56.94^{\dagger}$ \\
\hline
\end{tabular}

$\S$ Significantly greater proportion of RFS than present study results $(\mathrm{p}<0.001)$.

${ }^{\dagger}$ Significantly lower proportion of RFS than present study results $(\mathrm{p}<0.001)$. 

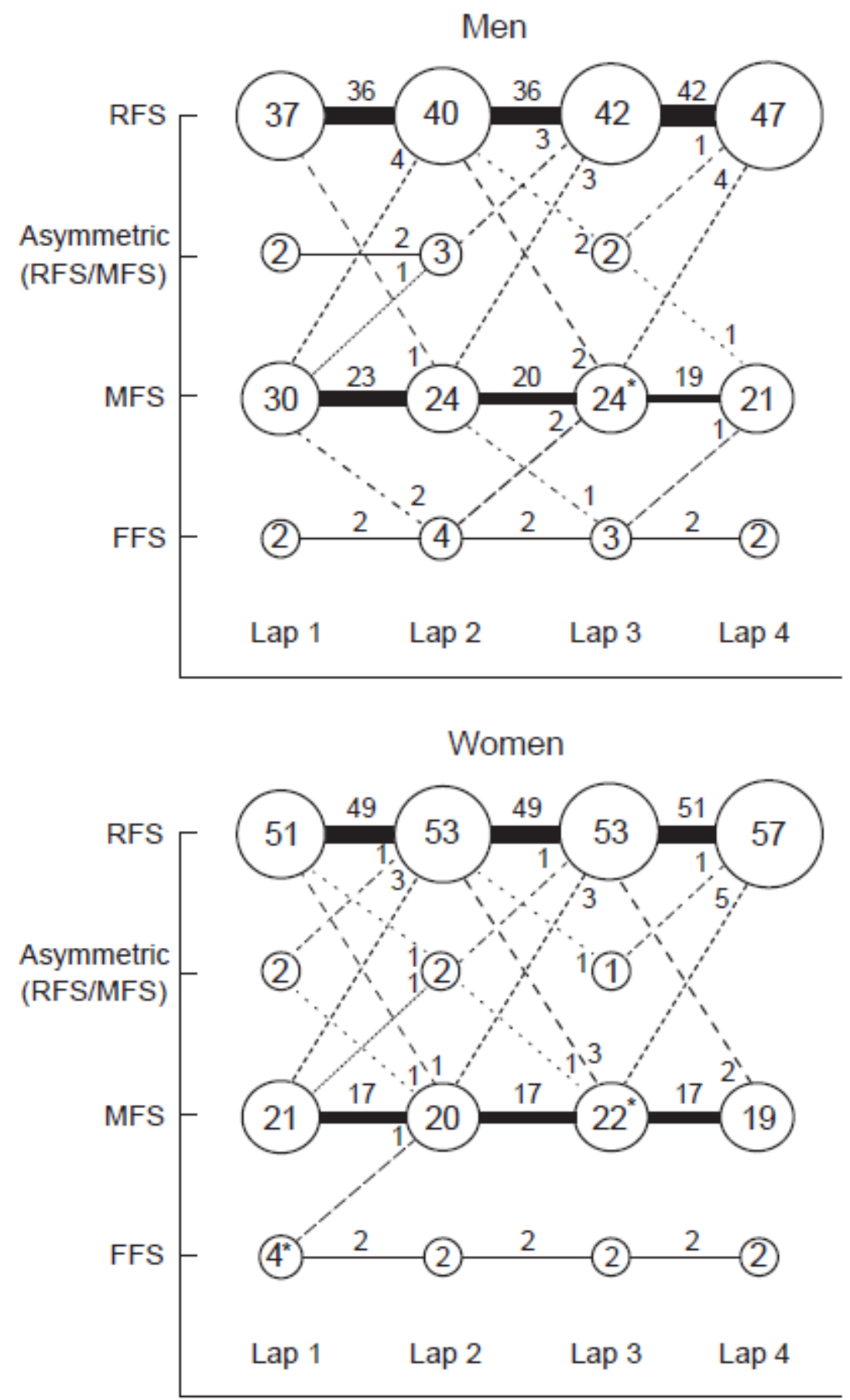

Figure 1. The number of athletes (shown in the circles) with each footstrike pattern for each lap and how many athletes switched pattern from one lap to the next (shown alongside the lines between the circles). The asterisks indicate where the previous or following totals differ because an athlete's footstrike pattern could not be identified on a particular lap (one man during Lap 4, and one woman during Lap 2). 

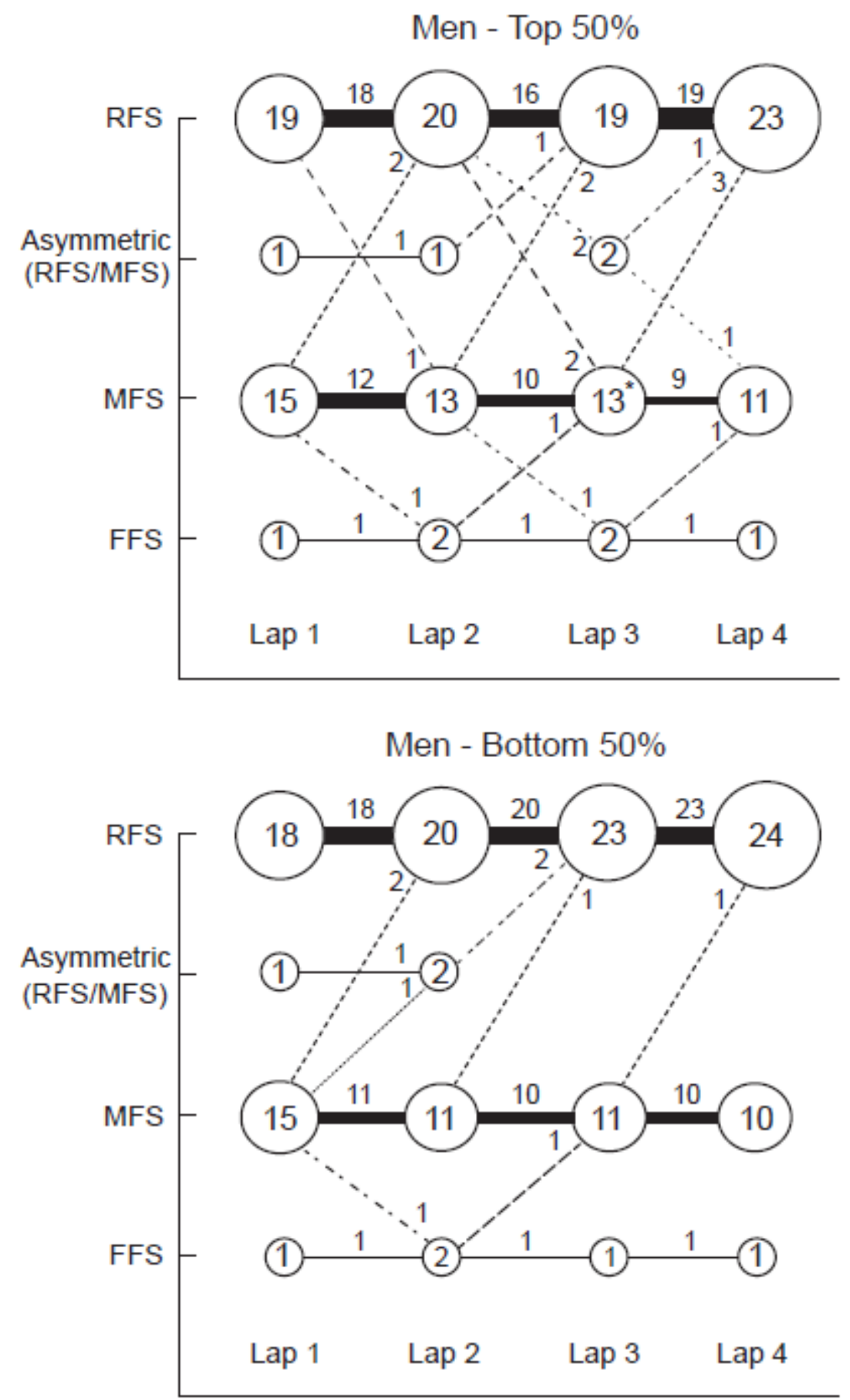

Figure 2. The number of top 50\% and bottom 50\% men (shown in the circles) with each footstrike pattern for each lap and how many athletes switched pattern from one lap to the next (shown alongside the lines between the circles). The asterisks indicate where the previous or following totals differ because an athlete's footstrike pattern could not be identified on a particular lap (one athlete during Lap 4). 

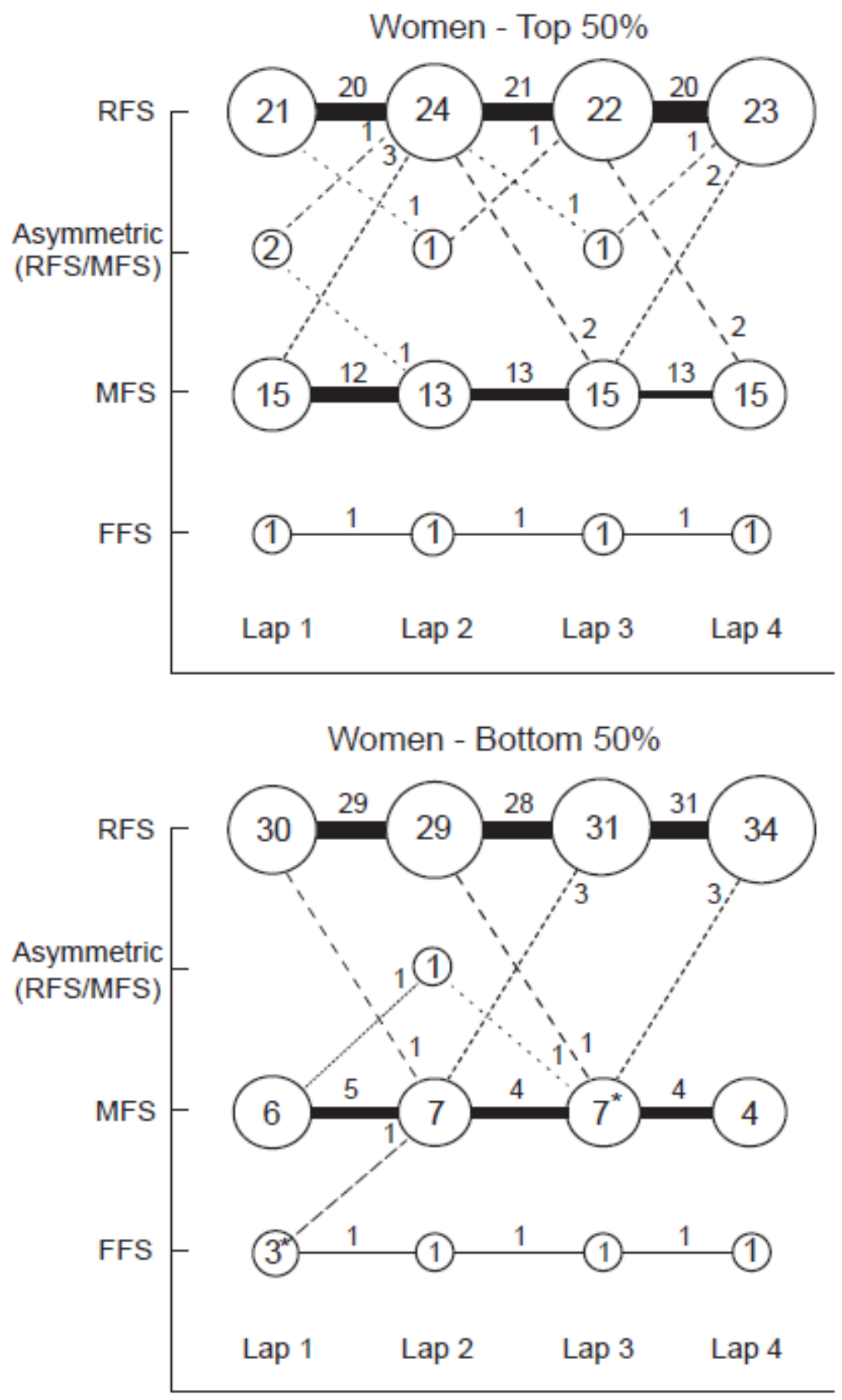

Figure 3 . The number of top 50\% and bottom 50\% women (shown in the circles) with each footstrike pattern for each lap and how many athletes switched pattern from one lap to the next (shown alongside the lines between the circles). The asterisks indicate where the previous or following totals differ because an athlete's footstrike pattern could not be identified on a particular lap (one athlete during Lap 2). 